\title{
A STUDY ON THE CLINICAL PROFILE OF SCORPION ENVENOMATION IN CHILDREN
}

\author{
K. Arivoli1, J. Ganesh ${ }^{2}$ \\ ${ }^{1}$ Assistant Professor, Department of Paediatrics, Chengalpattu Medical College and Hospital, Chengalpattu. \\ ${ }^{2}$ Associate Professor, Department of Paediatrics, Stanley Medical College, Chennai.
}

ABSTRACT: Scorpion envenomation is an acute, life-threatening medical emergency and a major public health problem in pediatric practice in many tropical countries including India.

METHADOLOGY: Study design was an observational prospective study was aimed to analyze the clinical presentation and outcome of children admitted with scorpion sting.

STUDY PERIOD: From August 2014 to July 2015.

SETTING: Semi-urban pediatric tertiary care-center.

STUDY POPULATION: All children less than 13 years of age admitted with history of scorpion sting.

STUDY PARAMETERS: Age, geographical distribution, timing of sting and arrival to the hospital, site of bite, time of the day, clinical features at presentation, complications like shock, myocarditis, peripheral circulatory failure, duration of hospital stay, treatment related factors like need for inotropes and mechanical ventilation or CPAP, laboratory parameters including blood sugar, ECG changes, echocardiography features and final outcome. All children were followed upto outcome defined as hospital discharge or death.

RESULTS: During the study period 68 children were recruited. $76 \%$ of children were admitted with nocturnal bites and majority of the bites were in the extremities. $67 \%$ were referred from peripheral centers. Pain at the bite site, cold extremities and excessive sweating were the common clinical features. $72 \%$ if the study group did not have any significant hemodynamic derangements. Shock, CCF with pulmonary edema and encephalopathy were the complications encountered. Sinus tachycardia was the commonest ECG abnormality in the study group. 19 children in the study group had evidence of decreased left ventricular ejection fraction. Mortality was $2.9 \%$.

CONCLUSION: Majority of the children with scorpion sting were referred to this Institute from primary and secondary levels hospitals. Delayed referral and non-administration of timely prazosin were common in the referrals. Administration of steroids and antihistamines is still followed by some physicians for scorpion envenomation.

RECOMMENDATION: There is an urgent need to create awareness about timely use of Prazosin in children with scorpion envenomation. Physicians working in peripheral centres need to be sensitized on timely administration of the drug and early referral to a tertiary care center.

KEYWORDS: Scorpion Sting, Clinical Symptoms, Envenomation,Treatment, Children, South India, Referrals.

HOW TO CITE THIS ARTICLE: K. Arivoli, J. Ganesh."A Study on the Clinical Profile of Scorpion Envenomation in Children”. Journal of Evolution of Medical and Dental Sciences 2015; Vol. 4, Issue 90, November 09; Page: 15522-15526,

DOI: $10.14260 /$ jemds/2015/2222.

INTRODUCTION: Scorpion stings are an acute, lifethreatening medical emergency and a major public health problem in pediatric practice in many tropical countries including India. It is a common problem, especially in villages around Chengalpattu. Among 86 scorpion species in India, Mesobuthus tumulus - the "red scorpions "are more prevalent and Black scorpion Palmaneus Gravimanus are also common. The venom of red scorpion is more likely to cause myocardial dysfunction and life-threatening complications such as respiratory, neurological and cardiovascular compromise and their bites are common in rural India.Black scorpion sting causes severe pain with mild swelling, sweating, local fasciculation, spasm of underneath muscle at the sting site

Financial or Other, Competing Interest: None

Submission 29-10-2015, Peer Review 30-10-2015,

Acceptance 31-10-2015, Published 06-11-2015.

Corresponding Author:

Dr. K. Arivoli,

Assistant Professor

Department of Paediatrics,

Chengalpattu Medical College and Hospital,

Chengalpattu.

E-mail: arivoli1972@gmail.com

DOI: $10.14260 /$ jemds $/ 2015 / 2222$. and transient cardiacinvolvement.In India, systemic envenoming signs andmortality rates are dramatically higher inchildren.[1-3]Envenomation rates have not changed greatly in recent decades but varied studies have shown different age distribution for scorpion stings. Children are mostly ambulatory and have explorative attitude and hence they have greater chances of envenomation. Mortality is now decreasing with timely intervention and referral.[2,3] But due to the lack of adequate emergency medical facilities, morbidity and mortality rate of scorpion envenomation is still high in rural areas. Hence we have chosen this study in a semi-urban located tertiary referral center of the state of Tamil Nadu in India.

METHODOLOGY:This descriptive study was conducted at pediatric intensive care unit (PICU) of a semi-urban referral center in South India. This study was conducted during August 2014 to July 2015 for a period of one year. All consecutive children admitted with history of "Definite" scorpion sting were recruited. Inclusion criteria: All children less than 13 years with scorpion sting. Exclusion criteria: Children admitted with history of unknown bite, Maneuver: All consecutive children fitting in with inclusion criteria were taken up for study after study parameters were collected in the pre-tested questionnaire. 
After study parameters, social demographic parameters like age, gender, place of residence, time of bite, location where bite has occurred and site of bite. Clinical parameters included heart rate, respiratory rate, blood pressure, oxygen saturation, sensorium, , priapism., salivation, vomiting, sweating, cold extremities and pupil size .Laboratory parameters considered were blood sugar, chest x-ray, ECG, echocardiography etc., Complications like autonomic storm, shock, myocarditis, encephalopathy or intra-cranial bleed, need for assisted ventilation, need for inotropes, hospital acquired infection, nosocomial sepsis and death were recorded. Following are the definitions used for study parameters:

Age was categorized as infant $<1 \mathrm{yr}$, pre-school 1-5years and school age as beyond 5 years, Setting as urban or rural according to the infrastructure they have in their locality. Time of bite -from $7 \mathrm{AM}$ to $7 \mathrm{PM}$ taken as day time and from 7PM to 7AM taken as dark. Site of bite is taken as in extremities, trunk, head and neck and in multiple sites. Location where bite incidence occurred: outdoor - defined as area beyond the house or its compound or nearby. Indoor defined as in the house or within the compound or play area and there on.

Color of scorpion identified as Red, Black or others. Information on Pre-hospital therapy with prazosin, antihistamines, steroids, paracetamol etc, referral details, prereferral details, mode of transport is also collected. Heart rate, bradycardia, tachycardia defined as per Pediatric Advanced Life Support (PALS).[4] Respiratory rate- bradypnea, tachypnea as defined as PALS.

Saturation below $94 \%$ is defined as hypoxemia by PALS and 02 supplementation is given Blood pressure as for age related chart as in PALS. Priapism, Sweating, salivation, vomiting, neurological status were assessed on admission and was followed up. CRT defined as normal if $<2$ seconds.

Children admitted were clinically classified according to Abroug's classification [5]

- Grade I-Pain and/or paresthesia at the scorpion sting site.

- Grade II-Fever, chills, excessive sweating, nauseavomiting, diarrhea, hypertension and priapism.

- GradeIII-Cardiovascular, respiratory, and/or neurologic symptoms. (Such as cardiogenic shock, pulmonary edema, altered consciousness and convulsive crisis).

ECG- rate, rhythm, PR interval, ST changes, T wave changes were recorded. Echocardiogram was done to assess the ejection fraction. Chest $\mathrm{x}$ ray for cardiomegaly, pulmonary congestion, pleural fluid. Complications like myocarditis and shock as defined as in PALS and hospital acquired infections were recorded. Children with shock were given 10-20 ml per $\mathrm{kg}$ NS as tolerated and started on inotropes when needed. Children with persistent shock despite inotropes were categorized as refractory shock. All children were followed up upto discharge or death, which is defined as outcome.

Data were analyzed with Epi-INFO -7 version statistical packages. The study was approved by the institute ethical committee. Informed written consent was obtained from the care giver or parents of the children whom participated in this study.

\section{RESULTS:}

Epidemiological Findings: Scorpion sting constituted 68 admissions in PICU during the period of 1 year (August 2014 July 2015). $79.1 \%$ (54) of the cases presented during summer months. Nearly $3 / 4^{\text {th }}(76.4 \%)$ of the study group had nocturnal bites. The mean age of the study group was 3.9 years (+/-SD) ranging from 4 months to 12 years. $63.2 \%$ of children were 2 to 5 years of age. Gender distribution revealed a slight male preponderance with a male female ratio of 1.6:1. Demographic parameters have been shown in (Table 1,2)

DISCUSSION: The socio-demographic factors and the factors like age of incidence, outdoor bites, extremities being the commonest site of sting, seasonal increase of cases were comparable to various studies.[6,7]. Admission of more than $50 \%$ of cases are of Class - I in our center may be unique to semi-urban centers which serve round the clock and depicts the mind set and awareness of patients to reach to a higher center in case of envenomation.

Pain is the commonest symptom which ranged between within few minutes to hours. ECG helps in diagnosis of fatal conduction disturbance, ischemia and very importantly tachycardia is the commonest finding usually seen with in first 4 hours and may persist for 24-72 hours.Bradycardia was noted in only 7 patients $(10.2 \%)$ at admission but Biswalet al. reported bradycardia in $3.5 \%$ of cases. ${ }^{(8,9)}$ Priapism was noted in nearly $1 / 3^{\text {rd }}$ [30.9\%] of male children. But Bawaskar et al. has noted occurrence of this clinical symptom in as many as $10 \%$ of patients and hyperglycemia was documented in $85 \%$ of our cases, and this is similar to studies by Balasubramaniam et al.[10-11]

Radiographic changes suggestive of pulmonary edema has been seen even within 3-4 hours of sting, even when asymptomatic as analyzed by various studies including Mahadevan et al..Pulmonary edema is a life threatening complication following scorpion sting by Mesobuthus tamulus species. It develops within 30 mins to 3 hours following a sting. Pulmonary edema may be due to both cardiogenic and noncardiogenic causes. Occurrence of pulmonary edema in the study is $8.8 \%$ and is similar to Bawaskar .et al.

Echocardiography revealed left ventricular systolic dysfunction in about 30 percent of cases by Biswalet al. Since the introduction of use of vasodilators prazosin, scorpion antivenom and intensive care management the fatality in scorpion envenomation has dropped to $<2-4 \%$. ${ }^{[9]}$ Prazosin is widely used and its beneficial effects in scorpion sting cases have been reported from endemic regions of India.

Still physicians from rural areas are less aware about its usage and its effect on reducing the morbidity significant reduction in morbidity and mortality due to scorpion sting envenomation has been achieved by use of prazosin. Delay in administration of Prazosin, severe hemodynamic compromise at admission might contribute to higher mortality.

The severity of envenomated children could be related to their smaller body mass and decreased physiological reserves compared to adults, making them predisposed to develop the most common systemic symptoms. Supportive therapy consist of conventional management of left ventricular failure and pulmonary edema. Observations of, Anand Kumar, et al. confirmed that administration of scorpion antivenom and prazosin within 4 hours of sting can reduce the cardiovascular morbidity and mortality [12]. The usefulness of prazosin therapy in this condition was scientifically established in mideighties in India. The experimental evidence of Gueron confirmed the clinical experience of Bawaskar and Bawaskar 
(Personal communication).

However Case fatality rates in children due to scorpion sting are declining after prazosin was introduced as the first line of management.[13-14] Since a significant proportion of children were admitted with referral but having not received Prazosin only indicates that there is an urgent need to create awareness among physicians about earlier usage of Prazosin to decrease the mortatility and morbidity in scorpion envenomation.

Children who received steroid and antihistaminics had a higher mortality than the cases who did not receive any treatment.Even in those who received prazosin when along with steroid and antihistaminics had a significantly higher mortality, than those who did not receive any drugs before admission. Antihistaminics and dexamethasone alone or in combination are known to potentiate the effect of catecholamine in CVS and CNS and worsen encephalopathy.cases died in our study were of similar case situations.

However the small numbers treated and died could not relate any statistical significance in this study. Severity of scorpion sting occur in children with $3.9-10 \%$ fatality irrespective of intensive care management from Israel, Turkey and India.[14] which has been the similar outcome of our morbidity $2.9 \%$.

Among the 68 studied cases, 2 deaths were registered, all of which belonged to severity class III at admission. The average time elapsed between sting and admission to the hospital was five hours (range: 2 to 19 hours).The need of the hour is to reduce morbidity and mortality by earlier administration of Prazosin to scorpion sting envenomation, among which myocardial dysfunction is most important.

Limitation of the Study: Anti-scorpion venom was not used in our study due to non-availability.

CONCLUSION:The present study shows that children should have supervised play when it is outdoor. Early hospitalization and administration of accurate dose of scorpion antivenom, prazosin and closely monitoring the victim in intensive care unit might help to reduce mortatility. Risk of Mortality was high in children if they arrive at the hospital late ( $>4$ hours) and who has received steroid and antihistamines prior to referral.

There is need to create awareness among the physicians at primary and secondary level hospitals with regard to timely use of Prazosin in children with scorpion envenomation. Peripheral hospitals need to have strict protocols to be followed with regard to indication for referral to higher centers and to avoid unnecessary referrals to these centers.

\section{RECOMMENDATION:}

1. Need to create awareness among physicians at primary and secondary level centers regarding the use of Prazosin in scorpion envenomation.
2. Standard guidelines to be made available in health care centers on when to refer children with scorpion envenomation and how to stabilize prior to transfer.

\section{REFERENCES:}

1. Chippaux JP, Goyffon M. Epidemiology of scorpionism: A global appraisal. Acta Trop. 2008;107:71-9.

2. Blum A, Lubezki A, Cslarovsky S. Black scorpion envenomation: two cases and review of the literature. Clin Cardiol1992;15:377-78.

3. Isbister GK, Bawaskar HS. Scorpion envenomation. N Engl J Med. 2014;371:457-63.

4. The American Heart Association (AHA) Pediatric Advanced Life Support (PALS) program- AHA guidelines for pediatric resuscitation - 2010

5. Abroug F, Nouira S, Saguiga H. Envenomations scorpionniques: avences chimiques, physiopathologiques et therapeutiquis. Monograph 1994;1- 68.

6. Mahadevan S. Scorpion sting. Ind. Ped, May 2000; 37: 504-14.

7. Das S, Nalini P, Ananthkrishnan S, et al. Scorpion envenomation in children in Southern India. J Trop Med Hyg 1995;98(5):306-08.

8. Biswal N, Mathai B, Bhatia BD: Scorpion sting envenomation: complication and management. Indian Pediatr 1993; 30(8); 1055-59.

9. Biswal N, Charan MV, Betsy M, Nalini P, Srinivasan S, Mahadevan S. Management of scorpion envenomation. Pediatrics Today 1999; 2: 420-426.

10. Balasubramaniam P, Murthy KRK. Liver Glycogen Depletion in Acute Myocarditis produced by Scorpion Venom (Buthus tamulus). Indian Heart J 1984;36(2):101-03

11. Radhakrishnamurthy K, Billimoria FR, Khopkar M, Dave KN. Acute hyperglycemia and hyper-kalemia in Acute Myocarditis produced by Scor-pion (Buthus tamulus) venom injection in dogs. Indian Heart J 1986; 38(1): 7174

12. Bawaskar. H.S; Diagnostic cardiac premonitory signs and symptoms of red scorpion sting, Lan-cet, 1982; ii: 55254.

13. Bahloul M, Chabchoub I, Chaari A, Chatara K, Jallel H, Dammak H, Ksibi H, Chelly H, Rekik N, Ben Hamida C, and Bouaziz M.Scorpion envenomation among children: clinical manifestations and outcome (analysis of 685 cases). Am J Trop Med Hyg 2010;83:1984-1092.

14. Bawaskar HS, Bawaskar PH. Prazosin in management of cardiovascular manifestations of scorpion sting. Lancet. 1986;1:+510-11. 


\begin{tabular}{|c|c|c|}
\hline Characteristics & No. of cases (N = 68) & Percentage (\%) \\
\hline \multicolumn{3}{|c|}{ Age distribution } \\
\hline Infant (<1 year) & 2 & 2.9 \\
\hline Pre-school & 43 & 63.2 \\
\hline School & 23 & 33.8 \\
\hline \multicolumn{2}{|c|}{ Sex } \\
\hline Male & 42 & 61.7 \\
\hline Female & 26 & 38.2 \\
\hline \multicolumn{3}{|c|}{ Geographical area } \\
\hline Rural & 50 & 73.5 \\
\hline Urban & 18 & 26.4 \\
\hline \multicolumn{2}{|c|}{ Table1: Epidemiological characteristics of study group } \\
\hline
\end{tabular}

\begin{tabular}{|c|c|c|}
\hline Characteristics & No. of cases $(\mathrm{N}=68)$ & Percentage (\%) \\
\hline \multicolumn{3}{|c|}{$\begin{array}{l}\text { Pre-hospital treatment } \\
\end{array}$} \\
\hline None & 12 & 17.6 \\
\hline Anti-histamines \& Steroids & 13 & 19.1 \\
\hline Anti-histamines, Steroids \& prazosin & 22 & 32.3 \\
\hline Prazosin alone & 21 & 30.9 \\
\hline \multicolumn{3}{|c|}{ Presenting symptoms } \\
\hline Pain at the site of sting & 54 & 79.4 \\
\hline Swelling & 7 & 10.2 \\
\hline Salivation & 25 & 36.7 \\
\hline Vomiting & 28 & 41.1 \\
\hline Priapism* & 13 & 30.9 \\
\hline Restlessness & 29 & 42.6 \\
\hline Diaphoreses & 48 & 70.5 \\
\hline Cold extremities & 57 & 83.8 \\
\hline Breathlessness & 15 & 22 \\
\hline Altered sensorium & 3 & 4.5 \\
\hline Convulsion & 2 & 3 \\
\hline Hypotension & 45 & 66 \\
\hline Hypertension & 7 & 10 \\
\hline Bradycardia & 7 & 10 \\
\hline Tachycardia & 38 & 55 \\
\hline Hyperglycemia & 58 & 85 \\
\hline \multicolumn{3}{|c|}{ Table 2: Demographic features of the study group } \\
\hline
\end{tabular}

In the current study, extremities were the commonest site of sting. Red scorpion was the inflicting agent in 41(60.2\%). Children more than $50 \%$ of the children were bitten in the extremities. 47 children (69\%) of the study group were referred to our Institute from nearby hospitals in the surrounding $50 \mathrm{~km}$ area. 57.3\% (39 children) of admission were referred from adjacent district / taluk headquarters hospitals. 12 children (17.6\%) did not receive any treatment prior to referral and 13 children (19.1\%) received inappropriate pre-referral treatment such as steroids, diuretics and anti-histamines. Only 43 children (63.2\%) received prazosin prior to referral to the Institute.

Pain at the site of the sting was recorded in $89 \%$ of the study group which was managed with supportive treatment like Paracetamol. Other frequent presenting features included diaphoresis and cold extremities. With regard to severity 52\% in Class I while in Class II-33\% and Class III-15\% were noted on admission. Other clinical features are shown in Table- 3.All children with scorpion sting were observed for 48-72 hours for any deterioration. 


\begin{tabular}{|c|c|c|}
\hline Time of sting & $\begin{array}{c}\text { No. of cases } \\
\text { (N = 68) }\end{array}$ & $\begin{array}{c}\text { Percentage } \\
\text { (\%) }\end{array}$ \\
\hline Daytime (7am-7pm) & 27 & 39.7 \\
\hline Night (7pm-7am) & 41 & 60.2 \\
\hline \multicolumn{2}{|c|}{ Admission time after sting } \\
\hline$<2$ hours & 12 & 17.6 \\
\hline $2-4$ hours & 42 & 61.7 \\
\hline$>4$ hours & 14 & 20.5 \\
\hline \multicolumn{3}{|c|}{ Location of sting } \\
\hline Outdoor & 43 & 63.2 \\
\hline Indoor & 25 & 36.7 \\
\hline Red & Color of scorpion \\
\hline Black & 41 & 60.2 \\
\hline Others & 12 & 17.6 \\
\hline \multicolumn{2}{|c|}{ Site of bite } \\
\hline Head and neck & 18 \\
\hline Extremities & 36 \\
\hline Trunk & 10 \\
\hline Multiple sites & 4 \\
\hline Table 3: Clinical Features at admission \\
\hline
\end{tabular}

Children with hemodynamic compromise, tachycardia and breathlessness were observed for further management. $72 \%$ of the study group did not have any significant hemodynamic change and were kept for observation for 72 hours. 14 children were admitted after more than 4 hours of sting, and developed life-threatening complications in their course during the stay in the hospital like shock, myocarditis, pulmonary edema and encephalopathy. 6 of them had cardiovascular complications and 3 developed encephalopathy and improved. Children with shock responded to inotropic support of dobutamine up to $10-15 \mathrm{mcg} / \mathrm{kg} / \mathrm{min}$ infusion except 2 cases which did not improve and died within 4 hours of admission due to acute pulmonary edema and catecholamine refractory shock. Significant echocardiographic findings were encountered in 42 children of our study group and their hospital stays are shown in Table 4 . Mortality was $2.9 \%$ in the study group. The cause of death was catecholamine refractory cardiogenic shock and pulmonary edema.

\begin{tabular}{|c|c|c|}
\hline Characteristics & No. of Cases $(\mathrm{N}=68)$ & Percentage (\%) \\
\hline \multicolumn{3}{|c|}{ Abnormal CXR } \\
\hline Cardiomegaly & 21 & 30.8 \\
\hline Pulmonary edema & 6 & 8.8 \\
\hline \multicolumn{3}{|c|}{ Abnormal ECG } \\
\hline Sinus tachycardia & 42 & 61.7 \\
\hline Wide QRS complex & 9 & 13.2 \\
\hline \multicolumn{3}{|c|}{ Abnormal ECHO } \\
\hline Cardiac dilatation & 23 & 33 \\
\hline Reduced LVEF\% & 19 & 27 \\
\hline \multicolumn{3}{|c|}{ Shock management } \\
\hline None & 55 & 80.8 \\
\hline NS bolus & 6 & 8.8 \\
\hline Inotropes & 7 & 10.2 \\
\hline \multicolumn{3}{|c|}{ Need for respiratory support } \\
\hline None & 58 & 85.2 \\
\hline $\mathrm{CPAP} / \mathrm{MV}$ & 10 & 14.7 \\
\hline \multicolumn{3}{|c|}{ Duration of stay in hospital } \\
\hline$<3$ days & 56 & 82.3 \\
\hline$>3-5$ days & 12 & 17.6 \\
\hline \multicolumn{3}{|c|}{ Table 4: Clinical parameters during hospital stay } \\
\hline
\end{tabular}

